\title{
The relationship of Obesity and Periodontal disease among Urban Population of Biratnagar, Nepal
}

\author{
Dr Dhirendra Kumar Giri \\ Department of Periodontology, Nobel Medical College, Biratnagar, Nepal
}

Correspondence: Dr Dhirendra Giri; Email: dhirendragiri814@gmail.com

\section{ABSTRACT}

Introduction: obesity has become an alarming concern worldwide. Obesity is not only a cosmetic concern, it is a health risk that threatens an individual's wellness. As the prevalence of obesity increases so have the related health consequences.

Objective: To determine the association of obesity with periodontal disease using Body Mass Index (BMI) Asian version, Oral Hygiene Index (OHI) and Community Periodontal Index (CPI) to assess the periodontal health and oral hygiene.

Materials \& Method: Body Mass Index was determined for 300 patients visiting the Department of Periodontics. The oral hygiene status was assessed by using Oral Hygiene Index Simplified-1964. The Community Periodontal Index was used to assess the periodontal status with a CPITN probe. The demographic details were collected using open ended questionnaire which included age, sex, socioeconomic status, education whereas smoking and stress were included in the close ended questionnaire.

Result: The present study showed association of obesity with periodontitis. Males had higher prevalence of periodontitis. Similarly age and smoking also had a higher prevalence rate of periodontitis.

Conclusion: As an oral health care professional, preserving periodontal health is the utmost responsibility. Finding and controlling new risk indicators and eliminating them is one of the most important relevance of the present study. Obesity has been identified as one more risk indicator other than age, smoking and diabetes mellitus.

Keywords: Body Mass Index, obesity, periodontal disease

\section{INTRODUCTION}

Obesity is one of the most detrimental precursors of non-communicable disease of modern civilization.' The epidemic of overweight and obesity present a major challenge to chronic disease prevention and health across the life course around the world. ${ }^{2.3}$ The drastic change in lifestyle, food habit and quality of food in last thirty years could be considered as contributing factor towards obesity. Obesity is a complex, multifactorial and largely preventable disease. It is affecting over one third of world's population today. ${ }^{2}$

Recently obesity has also been suggested as risk factor for periodontitis. Periodontitis is a multifactorial disease characterized by an ongoing infection and inflammation of gingiva and destruction of tissue attachment and bone surrounding teeth. ${ }^{4}$

Several studies have described an epidemiological association between periodontitis and obesity adding another dimension to the etiology of periodontal disease. According to Saito et al; Japanese obese subjects were more likely to have periodontal disease. ${ }^{5}$
In recent decades obesity has emerged as health burden hence considering that it is important to determine the association between periodontal disease and obesity. ${ }^{6}$ Literature in this regard is lacking in Nepalese population which is considered to be at high risk for non communicable disease because of dietary changes and life style changes in last thirty years and hence the need of present investigation.

The present study aims to determine the association of obesity with periodontal disease using Body Mass Index (BMI) Asian version, $\mathrm{OHI}$ and $\mathrm{CPI}$ to assess the periodontal health and oral hygiene.

\section{MATERIALS AND METHOD}

The present cross-sectional study was conducted at Department of Periodontics, Nobel Medical College, Biratnagar. The patients were given information regarding their participation in the study. The data was collected by personnel interview and clinical examination after obtaining written informed consent. Ethical clearance was obtained from Ethical committee of Nobel Medical College. 
A convenience sample of 300 was selected from patients who visited the Department of Periodontics during January 2016 to December 2016. Patients with significant medical history, receiving anti-inflammatory medication or nutritional supplements undergoing weight loss therapy, pregnant and lactating women and those receiving periodontal therapy during preceding six month were excluded from the study. Only subjects above 18 years were considered for inclusion. The patients were screened for body weight, height, age, stress and smoking. Patients were divided into three groups according to age: $<30$ years, $30-45$ years and $>45$ years. To assess the socioeconomic status Kuppu Swamy scale to Nepal was used.7 Smoking habit was determined and stress was evaluated on the basis of their response.

Two dental surgeons were trained and calibrated to conduct the interview and to record the clinical data. Oral hygiene status was assessed using Oral hygiene Index Simplified-1964.8 Community Periodontal Index was used to assess the periodontal status using a CPITN probe.9 The demographic details were collected using open ended questionnaire which included age, sex, socioeconomic status, education whereas smoking \& stress were included in the close ended questionnaire. Data was analyzed using SPSS Version 16. Descriptive statistics was used to describe the subjects, and Chi Square test was used to determine the association between obesity and periodontitis.

\section{RESULT}

The study comprised of 300 participants including 120 males and 180 females. The prevalence of periodontal diseases according to socio-graphic variables, oral health parameters and clinical characteristics are shown in Table 1.

There were 140 obese and 160 non-obese subjects. Among obese group; 72(51.4\%) had periodontitis and among non-obese group; $43(26.8 \%)$ had periodontitis. The prevalence of periodontitis among different age group $<30,30-45$, $>45$ was $42.5 \%$. $46.2 \%$ and $50 \%$ respectively. According to gender distribution; 55(45.8\%) males had periodontitis and $72(40.0 \%)$ females had periodontitis.

According to the socio-economic status; the prevalence of periodontitis was found to be $25 \%$ in upper middle, $40 \%$ lower middle and $45 \%$ lower class. The study showed socio-economic status is inversely proportional to poor periodontal health.

There were 55 smoker and 245 non-smoker subjects; among them $63.3 \%$ of smoking group had periodontitis as compared to $22.5 \%$ non-smoking group.

The present study assessed 120 subjects with stress out of 300 reported. Among 120 subjects with stress; 79(65.8\%) had periodontitis.

Table 1: Characteristics of subjects according to the periodontal status $(\mathrm{N}=\mathbf{3 0 0})$

\begin{tabular}{|c|c|c|c|c|c|c|c|}
\hline \multirow{2}{*}{\multicolumn{2}{|c|}{ Parameter }} & \multicolumn{4}{|c|}{ Periodontal Disease } & \multirow{3}{*}{$\begin{array}{c}\text { Total } \\
160\end{array}$} & \multirow{2}{*}{$p$-Value } \\
\hline & & \multirow{2}{*}{$\begin{array}{c}\text { Yes } \\
68\end{array}$} & \multirow{2}{*}{$\begin{array}{c}\% \\
42.5\end{array}$} & \multirow{2}{*}{$\begin{array}{l}\text { No } \\
92\end{array}$} & \multirow{2}{*}{$\begin{array}{c}\% \\
57.5\end{array}$} & & \\
\hline \multirow{3}{*}{ Age (years) } & $<30$ & & & & & & \multirow{3}{*}{$0.001 *$} \\
\hline & $30-45$ & 37 & 46.2 & 43 & 53.8 & 80 & \\
\hline & $>45$ & 30 & 50.0 & 30 & 50.0 & 60 & \\
\hline \multirow{2}{*}{ Gender } & Male & 55 & 45.8 & 65 & 54.2 & 120 & \multirow{2}{*}{0.544} \\
\hline & Female & 72 & 40.0 & 108 & 60.0 & 180 & \\
\hline \multirow{3}{*}{ Socio-economic Status } & Upper middle & 15 & 25.0 & 45 & 75.0 & 60 & \multirow{3}{*}{$0.001 *$} \\
\hline & Lower middle & 32 & 40.0 & 48 & 60.0 & 80 & \\
\hline & Lower & 72 & 45.0 & 88 & 55.0 & 160 & \\
\hline \multirow{2}{*}{ Smoking } & Yes & 35 & 63.3 & 20 & 36.7 & 55 & \multirow{2}{*}{$0.001 *$} \\
\hline & No & 45 & 18.4 & 200 & 81.6 & 245 & \\
\hline \multirow{2}{*}{ Stress } & Yes & 79 & 65.8 & 41 & 34.2 & 120 & \multirow{2}{*}{$0.004^{*}$} \\
\hline & No & 36 & 20 & 144 & 80.0 & 180 & \\
\hline \multirow{2}{*}{ BMl } & Obese & 72 & 51.4 & 68 & 48.6 & 140 & \multirow{2}{*}{$0.001^{*}$} \\
\hline & Non-obese & 43 & 26.9 & 117 & 73.1 & 160 & \\
\hline
\end{tabular}

Table 2: Association of BMI with periodontitis

\begin{tabular}{|l|c|c|c|c|c|c|}
\hline \multirow{2}{*}{ Parameter } & \multicolumn{4}{c|}{ CPI } & \multirow{2}{*}{ Total } & \multirow{2}{*}{ p-Value } \\
\cline { 2 - 7 } & Non-disease & $\%$ & Disease & $\%$ & 140 & \multirow{2}{*}{$0.001^{*}$} \\
\hline Obese & 58 & 41.4 & 72 & 51.4 & 160 & \\
\hline Non- obese & 90 & 56.2 & 43 & 30.0 & \\
\hline
\end{tabular}

*Statistically significant at $\mathrm{p}<0.05$ 


\section{DISCUSSION}

Out of a total 300 subjects, 120 were observed to have periodontitis, and Oral Hygiene Index was found to be fair in age group $<30$ years. In the present study subjects categorized as obese $\geq 25 \mathrm{~kg} / \mathrm{m}^{2}$ were observed to have association with periodontal disease $(p=0.001)$. This finding was consistent with study done by Dalla Vecchia et al, where they found association between obesity and periodontitis. ${ }^{4}$

Our study utilized BMI classification for Asia-Pacific to determine the obesity. The modification suggest that $\mathrm{BMI} \leq 18.5$ indicate under-weight, 18.5-22 indicate normal, 23-24 over-weight, $\geq 25$ obese as compared to $18.5,18.5$ 24.9, 25-29.9, 30 for under-weight, normal, overweight, obese respectively. ${ }^{9-11}$

The study showed association between gender and periodontitits. Males having high prevalence of periodontitis as compared to females which is consistent with the study reported by Dalla Vecchia et al. ${ }^{4}$ There was increase in prevalence of periodontitis with advancing age. Our study matched with a study which stated age, smoking, diabetes mellitus are risk indications for attachment loss. ${ }^{12}$

We did not consider the information about the duration and number of cigarettes smoked. The present study contradicted the study conducted by Xu et al. ${ }^{13}$ where cigarette smoking was negatively associated with body weight indicated by BMI. Our study did not show any relation between weight and smoking.

It was observed that a majority of the subject who were examined belonged to the higher socio-economic status viz, upper middle and lower middle class subjects possessed good oral hygiene with minimal periodontal and gingival inflammation.

\section{CONCLUSION}

Finding and controlling the risk indicators and eliminating them is one of the most important relevance of the present study. Obesity has been identified as one more risk indicator other than age, smoking, and diabetes mellitus.

The past decade proved obesity as unavoidable risk indicator for diabetes mellitus and cardio-vascular disease. The present study confirms obesity as one of the risk indicator of periodontitis.

As oral health care professional, it is our responsibility to reduce the disease burden of obesity in the society by educating the people to adopt healthy life style and healthy diet.

\section{REFERENCES}

1. Dana L. Duren, Richard J. Sherwood, Stefan A. Czerwinski, Audrey C. Choh, Roger M. Siervogel, Wm. Cameron Body Composition Methods: Comparisons and Interpretation. J Diabetes Sci Technol. 2008; 2(6): 1139-46.

2. Hruby A, Hu FB. The Epidemiology of Obesity: A Big Picture. Pharmacoeconomics. 2015; 33(7):673-89.

3. Pi-Sunyer FX. Health implications of obesity. Am J Clin Nutr. 1991; 53(6 Suppl): 1595S-1603S

4. Dalla Vecchia CF, Susin C, Rösing CK, Oppermann RV, Albandar JM, Hirani V, Zaninotto P, Primatesta P. Overweight and obesity as risk indicators for periodontitis in adults. J Periodontol. 2005; 76(10):1721-8.

5. Saito T, Sashimazaki Y, Sakamoto M. Obesity and periodontitis. N Engl J Med 1998; 339:482-3.

6. Vaidya A, Shakya S, Krettek A. Obesity prevalence in Nepal: Public health challenges in a Low-Income Nation during an alarming worldwide trend. Int J Environ Res Public Health. 2010; 7(6): 2726-44.

7. Ghosh A, Ghosh T. Modification of Kuppuswamy's socioeconomic status scale in context to Nepal. Indian Pediatrics. 2009 ; 46 (12): $1104-5$.

8. Greene JG, Vermillion JR. The Simplified Oral Hygiene Index. J Am Dent Assoc. 1964;68(1):7-13.

9. World Health Organization. Oral health surveys: Basic Methods,4th ed. Geneva: World Health Organization 1997:6-39

10. World Health Organization. The Asia-Pacific Perspective: Redefining Obesity and its Treatment. Geneva: World Health Organization; 2000. Redefining Obesity and its treatment. Geneva: World Health Organization; 2000.

11. World Health Organization. Global database on body mass index: BMl classification. Geneva: World Health Organization; 2006. Available from: http://www.who.int/bmi/index.jsp?introPage=intro_3.html. [Accessed July 16th 2008

12. Grossi SG, Genco RJ. Periodontal disease and diabetes mellitus: a two-way relationship. Ann Periodontol. 1998; 3(1):51-61.

13. $\mathrm{X} \cup \mathrm{F}$, Yin XM, Wang Y. The association between amount of cigarettes smoked and overweight, central obesity among Chinese adults in Nanjing, China. Asia Pac J Clin Nutr 2007; 16:240-7. 